\title{
Scuole italiane all'estero: livros de leitura para as escolas italianas no Brasil (São Paulo/SP- 1911-1931)
}

\author{
Scuole italiane all'estero: reading books for italian schools in Brazil
}

(São Paulo/SP- 1911-1931)

Scuole italiane all'estero: libros de lectura para las escuelas italianas en Brasil

(São Paulo / SP- 1911-1931)

\author{
Claudia Panizzolo \\ Universidade Federal de São Paulo (Brasil) \\ https://orcid.org/0000-0003-3693-0165 \\ http://lattes.cnpq.br/7842950333039932 \\ claudiapanizzolo@uol.com.br
}

\section{RESUMO}

A proposta deste texto é pensar a história da educação privilegiando a investigação acerca da política nacionalista italiana e das propostas educacionais que para cá foram trazidas. Tem como objetivo investigar os valores veiculados e prescritos para o fomento da italianidade e dos laços com a pátria-mãe nos estudantes, crianças italianas e filhas de italianos, pertencentes ao grupo de imigrantes italianos que se fixou no núcleo colonial de São Caetano- SP, para tanto toma como fonte privilegiada a edição de 1910 do livro de leitura Piccolo Mondo destinado à quarta classe para o ensino de meninos e de meninas da escola elementar criada pela Società di Mutuo Soccorso Principe di Napoli. Este trabalho se insere em uma perspectiva amplamente difundida pela Escola dos Annales que possibilitou a abertura de novas fronteiras interpretativas, a ampliação das fontes documentais e o alargamento de horizontes investigativos, dentre os quais se destaca os estudos da cultura material. Os livros de leitura ao constituírem a cultura da escola, não integram essa cultura de modo arbitrário, pelo contrário, são organizados e utilizados com intencionalidade, como portadores de uma dimensão da cultura social mais ampla.

Palavras-chave: Livros escolares; Livros de leitura; Imigrantes italianos; Escolas étnicas; Escola Elementar. 


\begin{abstract}
This article proposal is to think about history of education highlighting the research on Italian nationalist politics and educational proposals brought to Brazil. Its goal is to investigate the values in those books in order to promote the Italian identity and the attachment to the mother nation on the Italian and Italian's children students who were part of an immigrant group living in São Caetano's colony. To do so the reading book Piccolo Mondo, for boys and girls of the fourth class in the elementary school created by the Società di Mutuo Soccorso Principe di Napoli, was investigated. This paper belongs to the Annales School perspective that opened new interpretative frontiers, enlarged the documental sources and investigation horizons, among which the studies of material culture is highlighted. By constituting the culture of the school, the reading books do not integrate this culture in an arbitrary way; contrariwise, they are used and organized purposefully as carriers of the broader social culture dimension.
\end{abstract}

Keywords: School books; Reading books; Italian immigrants; Ethnical schools; Elementary school.

\title{
RESUMEN
}

La propuesta de este texto es pensar la historia de la educación privilegiando la investigación acerca de la política nacionalista italiana y de las propuestas educativas que para aquí fueron traídas. Se trata de investigar los valores vehiculados y prescritos para el fomento de la italianidad y de los lazos con la patria madre en los estudiantes, niños italianos e hijas de italianos pertenecientes al grupo de inmigrantes italianos que se fijó en el núcleo colonial de São Caetano- SP, para tanto toma como fuente privilegiada la edición de 1910 del libro de lectura Piccolo Mondo destinado a la cuarta clase para la enseñanza de niños y niñas de la escuela elemental creada por la Società di Mutuo Soccorso Principe di Napoli. Este trabajo se inserta en una perspectiva ampliamente difundida por la Escuola de los Annales que posibilitó la apertura de nuevas fronteras interpretativas, la ampliación de las fuentes documentales y la ampliación de horizontes investigativos, entre los cuales se destacan los estudios de la cultura material. Los libros de lectura, al constituir la cultura de la escuela, no integran esa cultura de modo arbitrario, por lo contrario, son organizados y utilizados con intencionalidad, como portadores de una dimensión de la cultura social más amplia.

Palabras-clave: Libros escolares; Libros de lectura; Inmigrantes italianos; Escuelas étnicas; Escuela elementar. 
Parole di Mussolini

Dovunque è un italiano là è il tricolore, là è la Patria, là è la difesa del Governo per questi italiani ( BAGAGLI, 1933, p. 108). ${ }^{1}$

\section{Introdução}

De Nardi, Dal'Mas, Veronesi, Perrella, Biagi, Braido, Buso, Zambotto, Garbelotti são os sobrenomes de algumas das 76 crianças, meninos e meninas que no ano de 1923 estudavam na Escola mantida pela Società di Mutuo Soccorso Principe di Napoli e que além do clássico Cuore, de Edmondo de Amicis ${ }^{2}$ estudaram as lições contidas no Libro di letture Piccolo Mondo.

Muito provavelmente tais livros tenham integrado o conjunto de livros didáticos produzidos na Itália e enviados gratuitamente para le scuole italiane all'estero, ou seja, para as escolas italianos no exterior, denominação adotada pelo governo italiano ao tratar das escolas étnicas.

Entre fins do século XIX e as primeiras três décadas do século XX é possível encontrar indícios de distribuição e circulação de livros italianos entre os imigrantes e seus descendentes (LUCHESE, 2014; PANIZZOLO, 2016). Seguindo o programa curricular vigente na Itália, livros de leitura, de religião, de aritmética, de história pátria, de geografia, de cantos, de excertos literários entre outros atravessaram o oceano com a finalidade de serem distribuídos aos alunos das escolas étnicas italianas.

Como artefatos culturais que produzem sentido e significado o livro didático, o livro escolar, o livro de leitura ou o manual escolar (terminologia que varia de acordo com o período e estrutura do livro) é, de acordo com Choppin (2002), uma fonte privilegiada para a História da Educação por situar-se na articulação entre as prescrições impostas pelos programas oficiais e os discursos singulares dos professores. Neste sentido, os livros de leitura podem ser tomados como utensílios culturais que estabelecem elos e vínculos entre as estruturas mentais e as figurações sociais, ou no dizer de Elias (1994) entre a psicogênese e a sociogênese.

Neste texto, o interesse investigativo centra-se no estudo do Libro di letture Piccolo Mondo, letture per le scuole elementari de autoria de Fanny Romagnoli e Silvia Albertoni, livro produzido na Itália e publicado pela Editora Bemporad, merecendo destaque a longevidade da publicação, sendo sua última edição no ano de 2011.

A proposta deste texto é pensar a história da educação privilegiando a investigação acerca da política nacionalista italiana e das propostas educacionais que para cá foram trazidas. Tem como objetivo investigar os valores veiculados e prescritos para o fomento da italianidade e dos laços com a pátria-mãe nos estudantes, crianças italianas e filhas de italianos, pertencentes ao grupo de imigrantes italianos que se fixou no núcleo colonial de São Caetano- SP.

Ancorado nos referenciais da História Cultural e tendo a análise documental como procedimento adotado, toma como fonte privilegiada o livro Piccolo Mondo, relatórios sobre as escolas em São Paulo, além de ordenamentos legais sobre as escolas no exterior e sobre a produção e adoção de livros.

1 Palavras de Mussolini. Em toda parte que esteja um italiano ali está o tricolor, ali está a Pátria, ali está a defesa do Governo por estes italianos.

${ }^{2}$ Cuore, de Edmondo de Amicis foi publicado na Itália em 1886 e chegou ao Brasil sob as traduções de Ramalho Ortigão, Miguel Novais e João Ribeiro. Além das traduções foi tomado como fonte de inspiração por Julia Lopes de Almeida, João Lopes Neto, Coelho Neto, Viriato Corrêa, José Scaramelli, Romão Puiggari e Arnaldo de Oliveira Barreto. Circulou nas escolas étnicas italianas, para o ensino da língua italiana, mas, sobretudo, pela presença na obra das características destacadas por ASCENZI, SANI (2005, p. 15), sobretudo, pelo senso de aceitação das desigualdades e injustiça, pelo ideal de irmandade entre as diferentes classes sociais em nome de um princípio ético-espiritual de pertencimento a mesma nação, pela ética do dever e do trabalho, pelo culto aos valores e das tradições familiares e cívicas, e por conter os elementos de uma verdadeira religião laica da pátria. 
O texto está organizado em três partes: na primeira busca-se compreender a política italiana para as escolas no exterior; na segunda ajusta-se o foco para o Brasil, província/estado de São Paulo, Núcleo Colonial de São Caetano, especificamente, a Escola da Societá di Mutuo Soccorso Principe di Napoli para em meio ao emaranhado, conforme descreveu Duby ( 1993, p.28), localizar "restos de escritas que emanam do fundo das eras, como destroços de um completo naufrágio" para buscar uma primeira aproximação do processo escolar entre imigrantes italianos e seus descendentes em terras paulistas; na terceira empreende-se um estudo sobre a materialidade da obra estudada, com vistas a conhecer e desvendar a proposta educacional, bem como os valores nela prescritos.

\section{Parte prima: Le scuole italiane all'estero ${ }^{3}$}

A temática das escolas italianas no Exterior, suas funções, finalidades e normas de funcionamento, esteve segundo Salvetti (2014), presente nas discussões político-educacionais desde as primeiras décadas pós-unificação, e para compreender as motivações do Estado Italiano em criar e manter vínculos com as escolas italianas no Exterior é necessário considerar o projeto de construção de um Estado forte e de uma política externa que desse a ver tal poderio. A epígrafe inicial do presente texto, datada de 1933 pode ser tomada como um exemplo desse projeto nacionalista e expansionista de uma Itália presente além de seu próprio território, e, cujo povo ainda que emigrado deveria considerar como Pátria a Itália. Para tal intento conhecer a língua e preservá-la, manter vivos os símbolos nacionais, com seus vultos históricos, monumentos e paisagens se fazia premente para a manutenção dos vínculos entre os emigrados e a Pátria-mãe. O local eleito para levar ao termo e ao cabo tão importante projeto foi a escola, afinal era preciso inventar o italiano e nele criar o sentimento de italianidade, convertê-lo em "instrumento" de influência cultural e de penetração comercial.

A primeira legislação que se refere às escolas italianas no Exterior, segundo Floriani (1974) é de 1862, do Ministro das Relações Exteriores Durando, que autorizava a criação de um colégio em Alexandria, no Egito. Nos anos seguintes foram criadas escolas em Tunísia e Constantinopla (1863), em Esmirna e Samos (1864), em Atenas (1865), em Galatz e Sarajevo (1866) e em Tessalônica (1868) que se organizavam de dois modos, em escolas públicas inteiramente financiadas pelo governo italiano, e em escolas privadas laicas ou confessionais, geralmente vinculadas a associações italianas no exterior, que recebiam subsídios do governo italiano, desde que respeitassem os programas e os métodos didáticos e se subordinassem ao controle dos Cônsules e inspeções ministeriais.

Aos oito dias de dezembro de 1889, pelo Decreto Real n ${ }^{\circ} 6566$ Francesco Crispi, chefe de governo e ao mesmo tempo Ministro das Relações Exteriores aprovou o ordenamento das Régias Escolas Italianas para a bacia do mediterrâneo e as escolas italianas no Exterior. Segundo a concepção de Crispi a emigração apresentava potencial de força da nação, além de indicar as "condições de contribuir para o desenvolvimento do comércio exterior e, portanto, das exportações italianas, principalmente às Américas” (SALVETTI, 2014, p. 58).

Cabe destacar que a partir de 1870, com a tomada de Roma pelo Estado italiano, e a "conseqüente falta de reconhecimento do Estado liberal italiano pela igreja" (SALVETTI, 2014, p.59) para usufruir do subsídio governamental as escolas das missões religiosas no Exterior além de aceitar os programas, os manuais e as inspeções governamentais, deveriam ter em seus quadros professores laicos e que comprovassem titulação.

\footnotetext{
${ }^{3}$ Primeira parte: As escolas italianas no Exterior.
} 
O aumento do número das escolas italianas no Exterior após a Reforma Crispi, em 1889 gerou por conseqüência, o aumento de investimentos governamentais a elas destinados, ainda que tais subsídios permanecessem insuficientes para arcar efetivamente com o adequado funcionamento das escolas:

A rubrica "Subsídios às escolas italianas no exterior" passou de 270 mil liras em 1886-1887 a 1.033.710 em 1890-1891. Desse aumento todavia bem pouco foi às sociedades de beneficência e de mútuo socorro que mantinham as escolas italianas no Exterior: as escolas subsidiadas, de fato, continuaram recebendo sempre quantias miseráveis em relação às suas conspícuas exigências (SALVETTI, 2014, p. 61)

Embora a concentração maior de escolas continuasse na África e na Europa, ainda que a imigração para lá fosse escassa, houve aumento também na América Latina, sobretudo, na Argentina e no Brasil, no entanto, aqueles recebiam subsídios mais significativos do que estes, que ironicamente recebiam imigração numericamente muito superior.

No que se refere especificamente a São Paulo é possível flagrar aumento, ainda que os dados sejam esparsos e muitas vezes contraditórios. De acordo com Parlagrecco em 1906 em São Paulo estavam em funcionamento 92 escolas italianas (FANFULLA, 1906, p. 800). O professor Arturo Magnocavallo ${ }^{4}$ quando esteve em São Paulo a fim de visitar as escolas e institutos italianos e realizar um estudo preparatório para a fundação de um instituto de ensino médio, registrou no importante relatório ${ }^{5}$ enviado ao Conselho Central da Sociedade Dante Alighieri, que no ano de 1907, visitou as 54 escolas italianas existentes na cidade de São Paulo. Conforme dados apresentados por Trento (2009) na cidade de São Paulo em 1908 estavam funcionando 80 escolas italianas, o que representa um significativo aumento. O número de escolas italianas continuava a crescer. De acordo com o Anuário do Ensino do Estado de São Paulo (1909) existiam em funcionamento 85 escolas italianas na capital no ano de 1909, chegando em 1910 a 91 de escolas ( SÃO PAULO, 1910). Pepe (1916) baseado nos dados do Ministério do Exterior para o ano escolar de 1913-1914 afirma que havia na capital do estado de São Paulo 42 escolas italianas. Um número bem maior foi localizado por Trento (2009) que indica 121 escolas para o ano de 1913. A partir daí, o autor flagra um acentuado fechamento das escolas, permanecendo em funcionamento, 46 em 1924 e somente 25 em 1930.

A opção em subsidiar com recursos estatais a instrução dos italianos no Exterior suscitou muitas críticas e resistências, sobretudo, em meio ao movimento operário, ao que parece especialmente por dois motivos. O primeiro provavelmente pela não compreensão da amplitude do fenômeno de emigração, e o segundo motivo pela situação crítica do ensino público na Itália, que apesar das leis de obrigatoriedade escolar, em vigor desde 1859 com a Lei Casati, reiterada em 1877 pela Lei Coppino, apresentava alarmantes índices de evasão escolar e analfabetismo:

\footnotetext{
4 Arturo Magnocavallo formado em Letras na Academia Científico- literária de Milão, havia iniciado a carreira como professor de História e Geografia na Régia Escola Técnica de Licata. Era à época um promissor vice-secretário do Ministério da Instrução Pública. A respeito de Magnocavallo consultar: DELL'AIRA, A. Longo estudo, grande amor: história do Istituto Medio Italo-Brasiliano Dante Alighieri de São Paulo. São Paulo: Annablume, 2011.

${ }^{5} \mathrm{O}$ relatório é constituído por quatro partes e anexos. A parte um denominada "As escolas primárias italianas e as escolas primárias brasileiras na cidade e no estado de São Paulo- propostas e soluções" encontra-se publicada em DELL'AIRA, 2011.
} 
Não se sabe porque o nosso governo continua mantendo tais escolas [italianas no Exterior]- escrevia o socialista Mariani em 1888, quase como se não soubesse onde pôr o dinheiro, quase como se não houvesse suficiente ignorância e analfabetismo em casa a prover, sem querer agir como rico com países que não têm necessidade alguma nem das nossas ajudas, nem dos nossos subsídios. (SALVETTI, 2014, p. 58).

A Lei Crispi foi substituída pela Lei Tittoni em 1910 e estabelecia o ensino religioso facultativo em horário extraclasse, reiterava o financiamento às escolas confessionais que se submetessem às inspeções governamentais, mantinha as escolas públicas na bacia mediterrânea e as escolas subsidiadas nas Américas, e determinava ainda que desde que respeitados os princípios de uma educação patriótica dos italianos e a conservação do idioma, as escolas poderiam se adaptar às necessidades dos países onde estavam instaladas.

Com a nova Lei, a contribuição às escolas subsidiadas permanecia irrisória, permanecendo necessária para a sobrevivência, o apoio financeiro das Sociedades de Mútuo Socorro, conforma manifestado pelo próprio Ministro Tittoni:

A estas Sociedades de Mútuo Socorro da América do Sul- defendia o ministro Tittoni- eu devo manifestar toda a gratidão do Governo italiano. De fato, são elas que fundaram e mantêm a maior parte das nossas escolas; e os nossos subsídios, espalhados numa área tão vasta, ao invés de serem contribuição real e eficaz para as despesas, devem somente ser considerados como uma contribuição moral e um encorajamento. (TITTONI apud SALVETTI, 2014, p. 71)

Em 1923, a Reforma Gentile modificava significativamente o ordenamento legal escolar italiano. No que se refere às escolas italianas no Exterior, manteve a "predominância de escolas estatais na bacia mediterrânea e na Europa sobre as escolas além-mar, subsidiadas-e condicionadas - especialmente por meio do envio de novos livros didáticos de marca fascista" (SALVETTI, 2014, p. 72), ainda instituiu o pronunciamento do solene voto profissional, no qual os professores prometiam educar seus alunos para amarem a Pátria e manifestarem devoção ao rei e às instituições italianas.

Em 1924 foram estabelecidos novos programas e fixadas diretrizes para as escolas italianas no exterior, priorizando a difusão da língua e cultura italiana e do sentimento nacionalista por meio da divulgação das 'grandes realizações' fascistas, considerada estratégia importante para estreitar vínculos entre os italianos no exterior (e não mais emigrantes) e a Pátria-Mãe, e entre a Itália e os países hospedeiros. Por meio do Decreto Régio n. 628 de 1927 outra iniciativa fascista para os italianos no exterior foi a implantação de um Comitê Interministerial para a expansão da cultura italiana nos países receptores. E ainda, em 1929, a criação da Direção Geral dos Italianos no Exterior e Escolas.

O fascismo buscou nas associações, nos jornais e nas escolas, segundo Bertonha (2001) "a socialização ideológica das crianças e jovens como forma de criar um "homem novo" (p.141), além de buscar recuperar os filhos dos emigrantes. As escolas mereceram especial atenção dos fascistas, ainda que, desde o período liberal, a rede escolar italiana no exterior, sempre tenha sido merecedora de um "especial carinho pelo governo de Roma (...) pois era considerada básica para manter a italianidade e os laços dos filhos de italianos nascidos no exterior com a Itália" (p. 48).

A seguir o texto dedica-se a apresentar umas das escolas italianas criadas no Brasil nas primeiras décadas do século XX, sob o ordenamento legal acima indicado e que provavelmente tenha recebido os parcos subsídios enviados pelo governo italiano. 


\section{Parte seconda: La Scuola Principe di Napoli in Brasile ${ }^{6}$}

O Núcleo Colonial de São Caetano foi fundado em 1877, na recém adquirida Fazenda de mesmo nome, pertencente ao Mosteiro de São Bento. No mês de julho de 1877, enquanto os emigrantes vênetos recrutados pelo governo brasileiro já se encontravam em viagem no vapor "Europa" a escritura da fazenda São Caetano era oficialmente transferida da Ordem de São Bento para o Governo Imperial. (MARTINS, 1992)

Esses imigrantes vênetos compõem um contingente bem maior de emigrantes saídos da península itálica rumo ao Brasil, e em expressiva quantidade para São Paulo. Vários foram os motivos do que ficou conhecido como período da Grande Emigração Italiana ocorrida entre as datas-marco da unificação italiana (1861) e do final da Primeira Guerra Mundial (1918), ganhando contorno a partir de fins dos 70, e tornando-se fenômeno de massa entre 1887 e 1902. Trento (1988, 2009) e Cenni (2003) apontam a miséria como a principal delas.

Os impostos sobre as propriedades e sobre o patrimônio, somados às altas taxas sobre a moagem dos grãos agravaram a miséria em que já viviam os camponeses. As condições de vida dos operários eram marcadas por condições bastante precárias de sobrevivência.

Nessas condições, segundo Alvim (2000) a emigração italiana se constituiu como um fenômeno importante de equilíbrio socioeconômico, por aliviar a pressão e as reivindicações sobre as cidades e indústria nascente, mas também, porque os expatriados enviavam dinheiro aos parentes o que em certa medida contribuía minimamente para afastar ou postergar uma rebelião social.

Os vênetos que desembarcaram do navio "Europa" na cidade portuária de Santos e foram levados para a Hospedaria dos Imigrantes ${ }^{7}$ na cidade de São Paulo, antes de serem conduzidos até o Núcleo Colonial São Caetano provavelmente enfrentaram difíceis condições econômicas como as descritas acima, tendo deixado sua terra, quando talvez não mais vislumbravam recursos para a sobrevivência. ${ }^{8}$

Teriam sido trazidos de trem de São Paulo para São Caetano, pela ferrovia São Paulo Railway Company, no entanto, como afirma Mimesse (2013), embora a ferrovia cruzasse as terras do Núcleo, "ainda não existia uma estação para o desembarque das pessoas, obrigando-as a saltarem do trem em movimento com seus filhos pequenos e suas bagagens"( p. 24). Novaes (1991) descreve, no entanto, outra situação:

Na tarde de 28 de julho de 1887, às 4 horas da tarde, mais ou menos, o maquinista da então São Paulo Railway, Casemiro Alonso, freou a pequena locomotiva ali próximo à grande curva conhecida hoje como do Matarazzo. Casemiro, debruçado na janelinha da locomotiva, observava aquele grupo de homens, mulheres e crianças que deixavam, com alguma dificuldade, os dois vagões de que se compunha o comboio, embaraçados com a bagagem e o cuidado com as irrequietas crianças. (p. 1)

Essa teria sido, no entanto, apenas uma das muitas dificuldades enfrentadas. De acordo com Martins (1992) e Mimesse (2013) os primeiros anos de vida no Núcleo

\footnotetext{
${ }^{6}$ Segunda parte: A Escola Príncipe de Nápoles no Brasil.

${ }^{7}$ De acordo com Paiva e Moura (2008) a Hospedaria de Imigrantes tinha por finalidade a recepção, a triagem e o encaminhamento do imigrante. Além dos serviços de alimentação e de alojamento havia o controle médico-sanitário, registro e direcionamento ao trabalho. "A permanência de imigrantes de trabalhadores nacionais era condicionada também pela oferta de trabalho, pela existência de problemas médico-sanitários ou pela disponibilidade de transporte. De acordo com os registros da Hospedaria, o tempo médio de permanência era de uma semana" (p. 30)

${ }^{8}$ Martins (1992) em sua obra apresenta os imigrantes que chegaram ao Núcleo Colonial de São Caetano como "camponeses pobres, camponeses sem terra, procedentes de uma das regiões mais pobres da Itália, naquela época- o Vêneto" (p. 29), e vítimas da exploração econômica, da expropriação territorial e precárias condições de vida já no país de origem.
} 
foram marcados por luta pela sobrevivência, pela construção das casas, pelo plantio da terra, pelo preparo do pasto, pelas reivindicações do que lhes havia sido empenhado pelo governo brasileiro, como o fornecimento de alimentos e o pagamento das diárias, além da luta incessante pela vida ameaçada pela doença e pela morte, sobretudo, pela mortalidade infantil ${ }^{9}$.

De acordo com Martins (1992) no Núcleo de São Caetano, lugar escolhido pelas elites como laboratório para a introdução do trabalho livre na província de São Paulo e no Brasil, ainda em tempos de escravidão, os imigrantes encontraram a doença, a morte e a grilagem, mas também manifestações de solidariedade. Ainda para o autor a religião católica e a italianidade foram elementos aglutinadores criando o sentido de caridade e de comunidade, enfim, o delineamento de uma identidade para o imigrante: católico e italiano. Ainda que essas duas identidades não coexistissem à época tão pacificamente, posto ter sido o Risorgimento Italiano feito em bases conflitivas e de hostilidades entre o Estado e a Igreja.

O conflito era entre o Estado e o Papa transcendendo, portanto, a vida local. Além do que nem o Estado Italiano, nem a Igreja Católica tinham presença contínua e efetiva no Núcleo São Caetano. No cotidiano da Colônia o imigrante italiano, cuja maioria nasceu antes da unidade nacional italiana, não se dava conta de tais conflitos.

A segunda geração de imigrantes que chegou vindo de Mantua, entre 1878 e 1892, além das doenças e da morte, encontrou condições ainda mais adversas. Diferentemente da primeira leva, esses não mais conseguiram lotes no Núcleo e consequentemente não receberam subsídios do governo para os primeiros seis meses de assentamento. Imersos em tantas dificuldades os imigrantes criam a Societá di Mutuo Soccorso Principe di Napoli pautada em princípios de solidariedade seculares presentes na revolução Italiana do Risorgimento. De acordo com Martins (1992) vários teriam sido os fatores motivadores da criação:

A falta de terras para as novas famílias que estavam chegando ou se formando, a crise da vinicultura derivada do praguejamento das parreiras e a agitação econômica como a inflação, produzida pelo "boom" fictício do chamado Encilhamento, de 1890 a 1892 (p. 194).

A Società di Mutuo Soccorso Principe di Napoli ${ }^{10}$, fundada em 1892 foi criada em meio e como consequência de uma série de mudanças econômicas, sociais e culturais que impactavam os imigrantes italianos levando à fundação de associações de mútuo socorro em várias localidades ${ }^{11}$. Em seu Estatuto definia:

Art. 1.- Si è costituita in San Gaetano uma Società di Mutuo Soccorso col nome di "Principe di Napoli",il cui scopo è l'unione, l'istruzione, La moralità ed il mutuo soccorso fra gli italiani. Il simbolo è la bandiera

\footnotetext{
${ }^{9} \mathrm{~A}$ causa da mortalidade infantil entre fins do século XIX e início do século XX era decorrente da febre amarela, a malária, a febre tifóide, a varíola, a coqueluche, mas também pela ausência de assistência médica, além da desnutrição. A esse respeito consultar: VERONA, F. Vida e morte dos operários de Schio em São Paulo: uma leitura dos Registros Obituários do Cemitério do Brás, de 1893 a 1895. In: CARNEIRO, M. L. T. et alii (orgs). História do trabalho e histórias da imigração. São Paulo: EDUSP/FAPESP, 2010, p. 267- 298.

${ }^{10} \mathrm{~A}$ este respeito consultar o capítulo O mútuo Socorro no nascimento da classe trabalhadora de Martins (1992).

${ }^{11}$ A este respeito ler: BIONDI ( 2011 ) que localizou entre 1878 e 1924 a existência de 44 sociedades mutualistas em São Paulo e nos centros urbanos periféricos de Santo Amaro, São Bernardo e São Caetano.
} 


\section{nazionale e col moto 'Principe di Napoli”.(SOCIETÀ DI MUTUO SOCCORSO PRINCIPE DI NAPOLI, 1922, p. 3) ${ }^{12}$}

A Società tinha funções bastante definidas, sobretudo, de assistência médica, tais como pagamento de um subsídio aos doentes, uma soma para as despesas hospitalares, pagamento de consultas médicas, pagamento de remédios e acompanhamento aos doentes feito pelos sócios em turnos. Além disso, a sociedade empenhava-se em pagar as despesas do funeral do sócio cuja família não estivesse em condições de custeá-las.

A Società abrigou em sua sede uma Scuola Italo Brasiliana (Escola Italo-Brasileira), sobre a qual pouco se sabe. Permeada por silêncios e fragmentos, os documentos localizados não nos contam sobre a sua fundação, a estrutura curricular, a organização do tempo e do espaço, os métodos, a cultura escolar. Em meio aos resíduos temos pistas de que sua fundação se deu entre 1911 e 1923. Até 1911 nada consta nas Atas da Società sobre a escola. Entre 1911 e 1929 as atas desapareceram! O que indica a forma muitas vezes pouco apropriada de guarda de documentos em Acervos. Em 1923 há uma foto registrando a existência da Escola. Na Ata de 9 de setembro de 1931 há uma deliberação para "oficializar ao Professor Cunha de ser gentil e desocupar a nossa Sede Social, inclusive porque não é pontual com o pagamento."

Figura 1- Scuola Principi di Napoli.

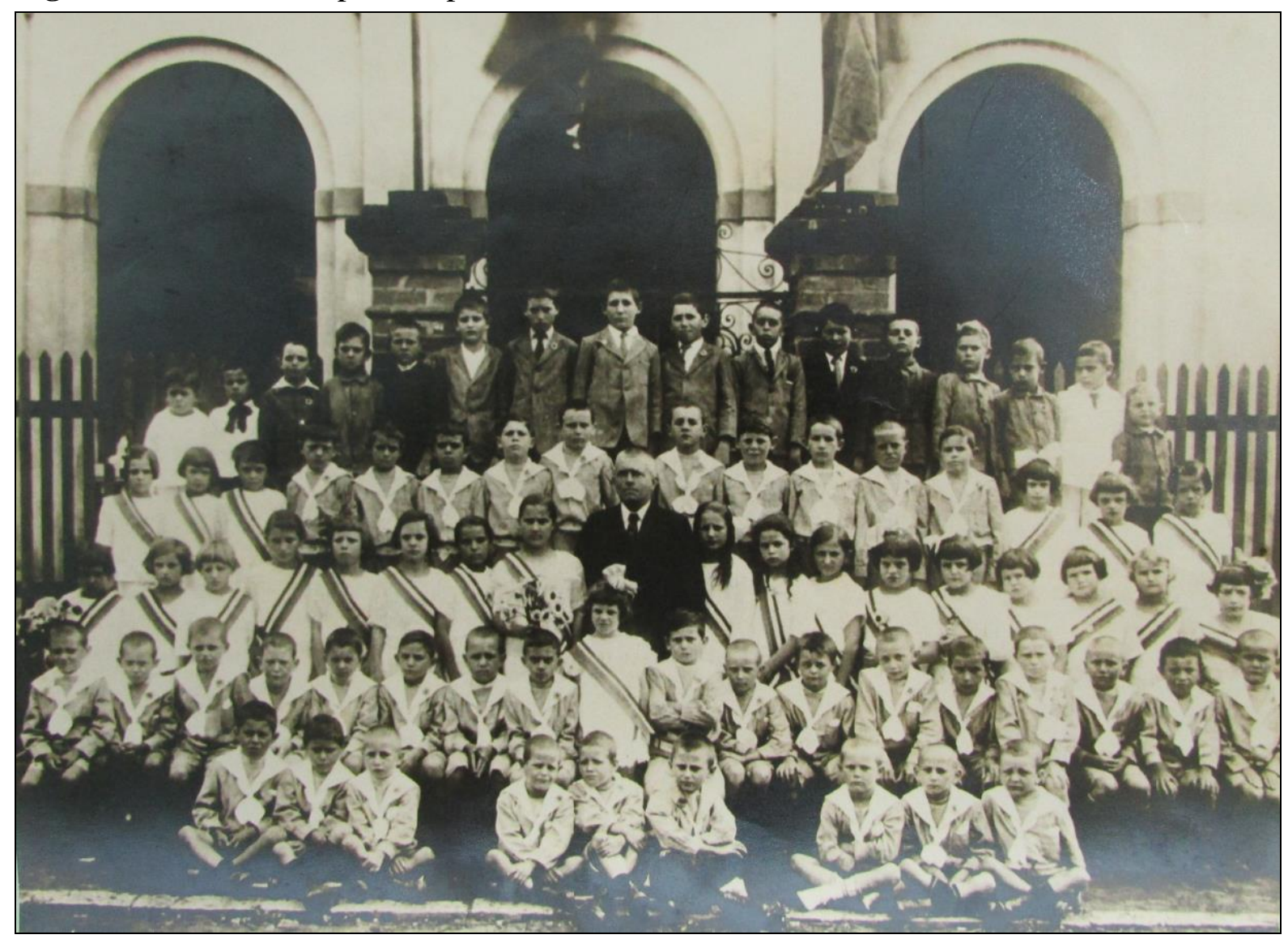

Fonte: Fundação Pró-Memória de São Caetano.

\footnotetext{
${ }^{12}$ Art. 1.- É constituída em São Caetano uma sociedade de mútua ajuda com o nome de "Principe di Napoli", cujo propósito é a união, a instrução, a moralidade e ajuda mútua entre os italianos. O símbolo é a bandeira nacional e com o motivo "Principe di Napoli” (Sociedade de Mútuo Socorro Príncipe de Nápoles, 1922, p. 3). (tradução da autora)
} 
Tal situação nos remete a pensar a situação das escolas italianas dessa época. O Professor Arturo Magnocavallo, após visitar as escolas elementares italianas da cidade de São Paulo em 1907, produziu um Relatório destinado ao Conselho Central da Società "Dante Alighieri" de Roma em que indica o estado de tais escolas como "misérrimo". Continua: "Somente na cidade de São Paulo existem atualmente cerca de setenta escolas primárias italianas. Muitas, aliás, demais, mas quantas merecem o nome de escola? Quantas são capazes de responder às mais modestas exigências da colônia?" (apud DELL'AIRA, 2011, p. 333). Afirma ainda, em verdade, não tratar-se de setenta escolas, mas de setenta pessoas que exercem o cargo, muitas vezes sem vocação e nem formação para tal.

A situação apresentada acerca das escolas de São Paulo nos permite interrogar se seria semelhante à escola da Società de Mutuo Soccorso Principe di Napoli. Seria um professor ou uma escola com vários professores? Qual a formação desse professor? Dele pouco se sabe. Seu nome era Giovanni Cardo. A esse respeito Novaes (1991) relata acerca de uma visita que o diretor do grupo escolar São Caetano fez à Escola da Sociedade Príncipe de Nápoles.

O nosso professor fez todos os alunos ficarem de pé e cantar o Hino Nacional brasileiro, e dezenas de vozes vibrantes encheram a grande sala de aula. Terminado o hino, o nosso mestre, inflado de satisfação e orgulho, voltou-se para o professor Perrenoud, cabeça erguida, queixo lançado para a frente, como a afirmar: aqui também são cultuados os símbolos nacionais brasileiros, embora a escola seja italiana! (p. 3)

O professor Giovanni Cardo, como tantos à época usava a vara ${ }^{13}$, mas como teria sido a estrutura curricular dessa escola? Ao que parece, além da língua italiana, aprendia-se o português, bem como os símbolos nacionais. Haveria História e Geografia italiana e brasileira no currículo? O método empregado seria o intuitivo propagado nas Conferências, na imprensa periódica e em implantação nas escolas-modelo e grupos escolares brasileiros?

A única foto localizada da Escola é de $1923^{14}$ e nela consta o nome do professor como sendo Giancarlo Carda. A turma estampada é de meninos e meninas. Seriam da mesma turma? As aulas funcionavam em regime de coeducação? As crianças estão todas uniformizadas e calçadas. A Società teria subsidiado o uniforme? As famílias imigrantes já estariam estabelecidas e com certa prosperidade, o que assegurava condições de manter as crianças na escola, longe do trabalho e com condições de arcar com tais despesas? Com relação ao salário do professor, quem o mantinha? Receberia o subsídio vindo do Ministério das Relações Exteriores da Itália? As próprias famílias pagavam o salário do professor Cardo? Perguntas que ainda permanecem sem respostas.

Mas é possível operar com a hipótese de que a Escola Principe di Napoli tenha se beneficiado com as contribuições para a instrução das crianças italianas ou filhas de italianas que viviam fora da península itálica, senão com subsídio em espécie, mas com material didático. A seguir será apresentando um desses materiais recebido pela Principe di Napoli, o livro de leitura Piccolo Mondo.

${ }^{13}$ Consta do acervo iconográfico da Fundação Pró-Memória de São Caetano a descrição: “O diretor era o Prof Giancarlo Cardo e a Secretária sua filha Maria Cardo. O livro didático para o grupo de alunos adiantados era Il Cuoro (sic), editado em italiano. Pedro (Pierim) Matielo levava as varinhas de marmelo para o professor, mas era o primeiro a experimentá-las como castigo devido à sua má conduta". ( Acervo 3917- A1 V5 P261)

${ }^{14}$ A foto encontra-se no Acervo Museu Histórico Municipal de São Caetano do Sul. 


\section{Parte Terza: Piccolo Mondo, letture per le scuole elementari}

$\mathrm{Na}$ Itália, a partir de 1880 foram organizadas diversas conferências pedagógicas pelo Ministério da Instrução com o objetivo de discutir os livros escolares, que em 1871 ultrapassavam dois mil títulos, número que quase dobraria em dez anos. Em 1890, o Ministro da Instrução Pública Paolo Boselli afirma que a situação editorial voltada à escola é uma "vera anarchia" e que desejava "mettere in ordine l'arruffata matassa", que pode ser traduzida como organizar aquele emaranhado de publicações (CHIOSSO, 2007, p.8).

Entre 1888 e 1916, conforme esclarece Barausse (2016) ocorreu um período de interesse e atenção à produção de livros destinados às escolas italianas no exterior, que se materializa no elenco de livros autorizados a serem utilizados nas escolas, publicado pelo Ministério das Relações Exteriores em colaboração com o Ministério da Instrução Pública.

Um desses muitos livros produzidos na Itália e destinados às escolas italianas no exterior é Piccolo Mondo, letture per le scuole elementari, para a escola feminina e masculina, composto por 7 livros: silabário, livro complementar ao silabário, primeiro livro de leitura, segundo livro de leitura, terceiro livro de leitura, quarto livro de leitura e quinto livro de leitura, de autoria de Fanny Romagnoli, professora integrante da Sociedade de professores bolonheses e Silvia Albertoni, publicado pela importante editora fiorentina Bemporad, que ao lado da Editora Mondadori detinham o maior número de livros aprovados pelo Ministério ( GALFRÉ, 2005).

Piccolo Mondo havia também sido aprovado para ser adotado nas escolas da península italiana. De acordo com Barausse (2008) a Circular Ministerial n. ${ }^{\circ} 75$, de 24 de setembro de 1900 aprovara o livro complementar ao silabário, com destaques às gravuras presentes. Os livros foram também indicados para províncias específicas, como por exemplo, para a Província de Pisa foi aprovado o silabário, além do segundo, terceiro, quarto e quinto livros de leitura (p. 559).

Embora ainda não disponha de informações sobre o número de edições, o exemplar localizado junto à documentação da Società é objeto de estudo neste artigo é de 1910 e referese ao volume indicado para o ensino de meninos e de meninas da quarta classe.

O livro, de formato pequeno (10 cm de largura por $17 \mathrm{~cm}$ de altura) é composto por 311 páginas distribuídas por 156 historietas e poesias, sendo mais de um terço delas ilustradas. Os textos são produzidos em sua maioria pelas autoras, havendo, no entanto, excertos de textos de outros autores italianos. Piccolo Mondo tem como núcleo central a família Rosati, o pai, o Sr. Rosati, engenheiro da ferrovia, a mãe, a Senhora Clotilde, mulher educada que cuida da educação das crianças e os três filhos, Alberto de treze anos, Isabella de onze e Giorgio de nove. As histórias se desenvolvem em torno do núcleo familiar, relacionamento entre pai, mãe e filhos, e dos âmbitos de socialização dos quais seus membros tomam parte, a escola e o círculo de amigos. Uma menor parte dos textos pode ser considerada avulsa, desvinculada deste universo acima descrito.

Piccolo Mondo apresenta uma preocupação com o ensino científico e com a valorização das Ciências Naturais. Nas historietas estão presentes temáticas voltadas à higiene, à saúde, à morte adulta e infantil, à nutrição, aos remédios e vacinas e às plantas. Um exemplo é a história de Giacinta, menina apresentada como de modesta condição, mas com uma aparência miserável: 
Anche la persona della Giacinta lasciava molto a desiderare per la pulizia: il visetto, che sarebbe stato molto bellino, sfigurava tra una selva di capelli mal pettinati, incolti; e il candore della pelle era velato di sudiciume; le mani poi parevano quelle di uno spazzacamino, e le unghie portavano um lutto perpetuo! (ROMAGNOLI, ALBERTONI, 1910, p. 12). ${ }^{15}$

Por meio de textos descritivos que têm por finalidade fornecer noções básicas ao leitor, a natureza é apresentada harmoniosamente organizada e classificada, com um funcionamento eminentemente prático. Alguns exemplos são as historietas sobre os elementos grandes e pequenos do mundo vegetal, sobre tipos específicos de plantas, além das plantas de uma horta e um bosque.

Há historietas voltadas aos saberes da Geografia, dessa forma as autoras dão continuidade ao ensino de Ciências Naturais, através de conteúdos que abordam diversos aspectos do meio ambiente. Os textos oferecem ao pequeno leitor algumas noções simples, especialmente sobre a água, presente em suas diferentes formas. A chuva é apresentada por vezes como branda e relaxante, e outras vezes, como assustadora com seus relâmpagos e trovões e que provoca inundações e calamidades:

Per tutto i segni della burrasca, da tutte le parti il racconto più o meno malinconico di quella notte, secondo che aveva più o meno ofesso il raccontatore. Ai Bagni, campi divorati dalla Lima, case, edifizi, piazze, muraglie, passeggi smozzicati e guastati. I luoghi di delizie, che pochi giorni innanzi formicolavano di tutta la quint'essenza del mondo elegante, ingombrati adesso di rena, di rottami e di ceppi voltolati dalla corrente.(ROMAGNOLI,ALBERTONI,1910, p. 188). ${ }^{16}$

As crianças são ensinadas também a respeitar e valorizar as estações do ano e seus respectivos climas e temperaturas, além dos diferentes tipos de relevos e o cultivo da terra. Com relação aos conteúdos que privilegiam o homem, Piccolo Mondo descreve as experiências humanas com a caça, a pesca, o trabalho na agricultura e na indústria, além das invenções como o trem e o navio.

Quanto aos conteúdos que privilegiam a vida em sociedade, as autoras apresentam um relato sobre a Exposição de 1898 que aconteceu em Torino para explicar as diferentes raças humanas, a caucásia, a etiópica, a amarela, a americana e a malásia. Ao fazê-lo, as autoras categorizam ${ }^{17}$ os seres humanos destacando os traços físicos observáveis nas crianças usando para isto, adjetivos

\footnotetext{
${ }^{15}$ Mesmo a pessoa de Giacinta deixava muito a desejar pela limpeza: o rostinho, seria muito bonito, era desfigurado em uma floresta de cabelo mal penteado, despenteado; e a brancura da pele era marcada com imundície; as mãos pareciam com as de um limpador de chaminés, e as unhas estavam em luto perpétuo! (ROMAGNOLI, ALBERTONI, 1910, p. 12). (tradução da autora)

${ }^{16}$ Pelos sinais de que a tempestade, de todas as partes o relato mais ou menos melancólico naquela noite, é de acordo com o que tinha cada um sofrido. Para os Bagni, campos devorados por limo, casas, prédios, praças, muros, ruas reduzidos a pequenos pedaços e destruídos. Os lugares belos, que poucos dias antes fervilhavam de toda a quintessência do mundo elegante, agora cheios de areia, de sucata e de troncos de árvores que retornaram da correnteza. (ROMAGNOLI, ALBERTONI, 1910, p. 188) (tradução da autora).

${ }^{17}$ Segundo Schwarcz (2002), a partir de 1870 diversas teorias, entre elas o evolucionismo e o darwinismo buscavam cada uma a seu modo, produzir uma teoria racial. Assim, se, de um lado, os evolucionistas monogenistas defendiam a origem una da humanidade e a possibilidade de "hierarquizar raças e povos, em função de seus diferentes níveis mentais e morais" (p.55), de outro lado, os evolucionistas poligenistas, embora acreditassem na "existência de ancestrais comuns na pré-história, afirmavam que as espécies humanas tinham se separado havia tempo suficiente para configurarem heranças e aptidões diversas" (p.55). A origem das espécies de Darwin deu margem a inúmeras interpretações a respeito dos famosos conceitos de evolução e hereditariedade, seleção do mais forte e competição, que foram acionados de diferentes formas e por diversos grupos para orientar os debates da época em torno de questões como civilização e progresso.
} 
como belo, feio, grosso, liso, crespo, e apresentando ao seu leitor uma verdadeira hierarquia entre os seres humanos, conforme se lê abaixo:

I bimbi di Terrasanta, gli Arabi e le fanciulle dell'alto Egito, colla pelle quase Bianca, col profilo regolare, cogli occhi bellissimi, somigliavano molto al tipo europeo, appartenendo infatti anch'essi alla razza caucasica; invece Le piccole Galla ci presentavano il perfetto tipo della razza negra o etiopica: labra grosse, naso schiacciato, capelli crespi e lanosi: erano brutine davvero [...]La razza gialla era rappresentata da ragazzetti cinesi; i piccoli avevano l'aria furba e non erano bruttissimi;ma i più grandicelli ispiravano poca simpatia, com quella pelle giallastra, tirata sugli zigomi sporgenti, com quegli occhi obliqui e di strana espressione, e quei capelli Neri e lisci, stretti in um lungo e sotille codine[...]Erano venuti all'Esposizione anche alcuni rappresentanti della razza americana o rosso-rame, che erano partiti dalla loro Terra del Fuoco, al sud dell'America Meridionale[...]Non vidi alcuna rappresentanza della razza malese, e non credo ce ne fosse. (ROMAGNOLI, ALBERTONI, 1910, p. 42-45) ${ }^{18}$

Ainda nesse mesmo texto, os países de origem das crianças são apresentados como semibárbaros ou completamente bárbaros, no entanto, por terem sido salvas como as crianças foram salvas pelos missionários italianos, que as libertaram da escravidão em que viviam ou da orfandade "alcuni avrebbero potuto insegnare l'accento a molti bimbi nati e cresciuti sotto Il bel cielo d'Italia" (ROMAGNOLI, ALBERTONI, 1910, p. 46) ${ }^{19}$

Esses textos sobre a vida em sociedade nos permitem compreender como uma realidade social é construída e pensada a partir das representações sociais determinadas pelos interesses dos grupos que as criam e que, portanto, não são neutras, ao contrário, são conduzidas por estratégias que visam legitimar seus discursos. Chartier (1994) as define como um conjunto de "representações coletivas que incorporam nos indivíduos as divisões do mundo social e estruturam os esquemas de percepção e apreciação a partir dos quais estes classificam, julgam e agem” (p. 104).

O ensino da História, e especificamente da História da Pátria, ocupa lugar de destaque nas páginas de Piccolo Mondo, provavelmente considerada pela elite intelectual que pensava a educação na Itália, como sendo uma disciplina fundamental para a nação recém unificada para a construção do patriotismo e do nacionalismo do povo italiano (dentro e fora da Itália). É ofertado ao leitor um passeio pelo país por meio de descrições e imagens de lugares e monumentos importantes da Itália: Caverna Del Farneto em Bologna; os canais e as gôndolas, a Scala dei Giganti, a Ponte dos Suspiros, a Ponte de Rialto, a igreja da Madona da Saúde, de São Giovanni e Paulo, a Basílica de San Marco, a Torre do relógio em Veneza; a Arena, a Piazza dell'erbe e a igreja de Santa Maria in Organo em Verona; o Duomo dedicado a San Ciriaco, a igreja de São Francisco e de Santo

\footnotetext{
${ }^{18}$ As crianças da Terra Santa, os árabes e as meninas do alto Egito, com a pele quase branca, com perfil regular, com seus belos olhos, pareciam muito com o tipo europeu, pertencentes, na verdade, também a raça caucasiana; enquanto que as pequenas atrações eram o tipo perfeito da raça negra ou etíope: lábios grossos, nariz achatado, cabelos crespos e com aparência de lã: eram feios de fato [...] A raça amarela foi representada por meninos chineses; os meninos tinham aparência astuta e não eram muito feios; mas os mais velhos inspiravam pouca simpatia, com aquela pele amarelada, esticada sobre maçãs do rosto salientes, com olhos oblíquos e expressão estranha, e com aqueles cabelos negros e lisos, presos em rabos de cavalo [...] Vieram à Exposição alguns representantes da raça Americana ou vermelho-cobre, que vieram da Terra do Fogo, na América do Sul meridional [...] Eu não vi qualquer representação da raça Malásia, e eu não acho que houvesse mesmo. (ROMAGNOLI, ALBERTONI, 1910, p. 42-45). (tradução da autora)

19 "alguns puderam ensinar o sotaque a muitas crianças nascidas e crescidas sob o belo sol da Itália" (ROMAGNOLI, ALBERTONI, 1910, p. 46). (tradução da autora)
} 
Agostinho, as ruas e praças de Ancona; a Via Nacional, a Via Roma, o Vesúvio em Napoli; o Etna em Catania; o Foro Romano, o Arco de Tito, o Arco de Constantino, o Foro Traiano, a Basílica de São Pedro, a Piazza de São Pedro e o Vaticano, a Fontana dell'acqua Paola em Roma etc.

Ao longo das historietas são apresentados também os heróis nacionais, de modo a unificar o país, através da construção de uma imagem idealizada, de uma representação com vistas a congregar diversos espaços e tempos e, sobretudo, unir o povo de diferentes regiões da península, sonho almejado pelo Risorgimento. As descrições das virtudes acompanhadas das imagens do Rei Umberto I, da Rainha Margherita, do Rei Vittorio Emanuele III e de Garibaldi estão presentes em Piccolo Mondo.

O livro de leitura era o único livro utilizado na escola primária brasileira, tanto para o ensino da leitura quanto para o ensino da Moral, do Civismo e da História Pátria, talvez o mesmo acontecesse nas escolas italianas no Brasil. Aprendia-se a ler lendo um determinado padrão de conduta e aprendia-se a amar a pátria lendo pequenas historietas, notícias biográficas e depois excertos de leitura sobre importantes episódios da história que contribuíam para a formação do amor à Pátria.

Cabia ao livro de leitura o desafio de edificar na recém unificada Itália a idéia de Pátria como o lugar onde as pessoas se identificam pela origem, costumes, língua e principalmente pelo sentido agregador e unificador da Pátria-mãe, que acolhe a todos, criando assim uma identidade comum. Nesse sentido, a temática da emigração tão presente na realidade social italiana também esteve presente no Piccolo Mondo. Os emigrantes são apresentados como os que foram praticamente constrangidos a abandonar a terra natal em busca de sobrevivência e trabalho, enfim para ganhar o pão em terra estrangeira: "essi hanno lasciato quanto di più caro avevano al mondo, il villaggio nativo, la casetta, i vecchi genitori, la chiesa, Il camposanto dove dormono tanti loro cari: tutto hanno lasciato; fra poco diranno addio anche all'Italia" (ROMAGNOLI, ALBERTONI, 1910, p. 234). ${ }^{20}$

E por fim, mas não menos importante, Piccolo Mondo apresenta um projeto civilizatório. As autoras destinaram significativo espaço para o aprendizado da civilidade, buscando, no dizer de Revel (1999, p.178) "ao mesmo tempo, disciplinar as almas por meio de coerção exercida sobre o corpo e impor à coletividade das crianças uma mesma norma de comportamento sociável" o que se faz por meio da transmissão de valores como bondade, caridade, paciência, trabalho, respeito aos mais velhos, ao mesmo tempo em que busca distanciar as crianças do orgulho, do apego aos valores materiais, da preguiça, da cobiça, entre outros sentimentos.

As páginas do Livro de leitura são repletas de crianças e adultos que sentem prazer ao praticar o bem ao próximo e em ajudar os mais necessitados. O sentimento de responsabilidade para com seus pertences e as obrigações para com os outros também são divulgados, ou seja, além de boas atitudes, espera-se da criança comportamentos, hábitos e valores significativos para a sociedade na qual está inserida. As histórias enfatizam que é necessário o conhecimento, o entendimento e a prática de bons comportamentos e virtudes para se viver bem, ou no dizer de Revel (1999) as historietas visam, sobretudo, moldar a criança para a necessidade de um código geral de civilidade.

O livro pode ser compreendido à luz do que Elias (1994, p.168) assevera acerca da não naturalidade das atitudes impostas pela sociedade às crianças, assim, quanto mais natural o padrão de delicadeza e vergonha parecer aos adultos e quanto mais "o controle civilizado de ânsias instintivas é aceito como natural, mais incompreensível se torna para os adultos que as crianças não sintam 'por natureza' essa delicadeza e vergonha". Dessa forma as crianças são chamadas a desenvolver o autocontrole, tornando automático "o comportamento socialmente desejável, uma questão de autocontrole, fazendo com que o mesmo pareça à mente do individuo resultar de seu

\footnotetext{
20 "eles deixaram o que de mais caro têm no mundo, a aldeia natal, a casa, os velhos pais, a igreja, o cemitério onde dormem muitos de seus entes queridos: tudo deixaram; logo dirão adeus também à Itália." (ROMAGNOLI, ALBERTONI, 1910, p. 234) (tradução da autora)
} 
livre arbítrio", sendo, portanto, "de interesse de sua própria saúde ou dignidade humana" (ELIAS, 1994, p. 153).

Das historietas de Piccolo Mondo emergem normas de convivência social e regras de condutas individuais e coletivas consideradas à época os pilares de uma sociedade "moderna", portanto, as autoras pretenderam, em vez de descrever a sociedade, transformá-la (CHOPPIN, 2002). Nesse sentido, a visão de infância e de crianças é idílica, revelando mais a imagem que se desejava do que a verdadeira imagem quer seja a imagem de uma criança forte, estudiosa, adaptada ao ambiente familiar, escolarizada, regrada, bem-comportada e higiênica.

\section{Considerações Finais}

A escola italiana mantida pela Sociedade de Mútuo Socorro Príncipe de Napoli foi importante para a manutenção da língua, para o ensino da escrita, para o culto da Itália como pátria dos imigrantes e de seus filhos, além de criar um sentimento de pertença, de compartilhamento de costumes e cultura, uma identidade italiana, uma italianitá, favorecendo a constituição de um piccolo mondo italiano no Núcleo Colonial São Caetano, que tinha como monumentos, heróis, língua e Pátria a Itália.

Esse conjunto de saberes a ensinar e condutas a incorporar ganha materialidade no livro de leitura Piccolo Mondo e, portanto, seu estudo possibilita a compreensão das preocupações sociais da época, das filiações ideológicas, além da apreensão das práticas educativas de ordem escolar, social e moral e das representações de sociedade e das crianças. Em suas páginas emerge um projeto ao mesmo tempo civilizatório e de constituição da italianidade.

O Livro de leitura estudado atende aos programas do Ministério da Instrução Italiana oferecendo noções de higiene, de ciências naturais, de história e geografia, além de dedicar aproximadamente metade de suas páginas para textos moralizantes, que buscam inculcar condutas morais e valores, civilizando os pequenos.

Compor os cenários das escolas italianas em São Paulo e nos núcleos coloniais de seu entorno, trazer à tona seus professores, as propostas curriculares, os mobiliários, os materiais pedagógicos, os livros estudados, enfim, o estudo sobre a materialidade escolar no contexto da escolarização para italianos e seus descendentes ainda muito intriga e suscita investigações que podem nos ajudar a revelar e compreender os dizeres e fazeres da escola primária no Brasil entre fins do século XIX e início do século XX.

\section{REFERÊNCIAS}

ALVIM, Z. M. F. O Brasil Italiano (1880-1920). In: FAUSTO, B.(org). Fazer a América. $2^{\mathrm{a}}$ ed. São Paulo: EDUSP, 2000. p. 383-418.

ASCENZI, A; SANI, R. Il libro per la scuola tra idealismo e fascismo: l'opera della Commisione centrale per l'esame dei libri di testo da Giuseppe Lombardo Radice ad Alessandro Melchiori (1923-1928). Milano: Vita e Pensiero, 2005. (Pedagogia e Scienze dell'educazione).

BARAUSSE, A. Livros didáticos e "italianidade" nas escolas italianas do Brasil: entre liberalismo e fascismo. Anais do XI Congresso Luso- Brasileiro de História da Educação. Porto: Centro de investigação transdisciplinar cultura, espaço e memória. 2016. https://doi.org/10.4000/nuevomundo.3720 
BARAUSSE, A. Il libro per la scuola dall'unità al fascismo: la normativa sui libri di testo dalla legge Casati alla Riforma Gentile (1861- 1922). Macerata: Alfabetica Edizioni, 2008. (Fonti e documenti 2).

BAGAGLI, C. Letture classe terza: scuole italiane all'estero. s/editora, 1933.

BIONDI, L. Classe e nação: trabalhadores e socialistas italianos em São Paulo, 1890-1920. Campinas: UNICAMP, 2011. https://doi.org/10.4000/nuevomundo.3720

BERTONHA, F. O fascismo e os imigrantes italianos no Brasil. Porto Alegre: EDIPUCRS, 2001.(Coleção História - 40).

CENNI, F. Italianos no Brasil: “Andiano in Merica”. $3^{\text {a }}$ ed. São Paulo: EDUSP, 2003.

CHARTIER, R. A história hoje: dúvidas, desafios, propostas. Estudos Históricos. Rio de Janeiro, v. 7, n. 3, p. 97-113, 1994.

CHIOSSO, G. L'Italia alfabeta: libri di texto e editoria scolastica tra otto e primo Novecento. Quaderni del CIRSIL, n. 6, p. 1-23, 2007.

CHOPPIN, A. O historiador e o livro escolar. História da Educação, Pelotas, v.6, n.11, p.524, 2002.

DELL'AIRA, A. Longo estudo, grande amor: história do Istituto Medio Italo-Brasiliano Dante Alighieri de São Paulo. São Paulo: Annablume, 2011.

DUBY, G. A história continua. Trad.: Clóvis Marques. Rio de Janeiro: Jorge Zahar Ed. I UFRJ, 1993.

ELIAS, N. O processo civilizador: uma história dos costumes. Rio de Janeiro: Jorge Zahar, vol. 1, 1994.

FANFULLA. Il Brasile e gli italiani. Firenze: R. Bemporad \&figlio, 1906.

FLORIANI, G. Scuole italiane all'estero: cento anni di storia. Roma: Armando Editore, 1974.

GALFRÉ, M. Il regime degli editori: libri, scuola e fascismo. Roma: Editori Laterza. 2005.

LUCHESE, T. Â. Produção, circulação e preservação de livros escolares italianos no Brasil (1875-1945). Anais do X Congresso Luso Brasileiro de História da Educação- COLUBHE. Paraná: Curitiba, 2014, p. 1-15. https://doi.org/10.1590/2236-3459/68894

MARTINS, J.de S. Subúrbio: vida cotidiana e história no subúrbio da cidade de São Paulo: São Caetano, do fim do Império ao fim da República Velha. São Paulo/São Caetano: Hucitec/ Prefeitura de São Caetano do Sul, 1992. (Série Histórica 3). https://doi.org/10.11606/issn.2316-9141.v0i127-128p211-213

MIMESSE, E. As aventuras e desventuras cotidianas das crianças em São Caetano no início do século XX. In: MIMESSE, E. (org). Bambini brasiliani: a infância das crianças italianas e ítalo-brasileiras. Jundiaí: Paco Editorial, $2013 . \quad$ p. $19-54$. https://doi.org/10.5585/eccos.n32.4482 
NOVAES, M. C. Nostalgia. São Paulo/São Caetano do Sul: Meca/ PMSCS, 1991. (Série histórica São Caetano do Sul). https://doi.org/10.11606/d.6.2001.tde-02022011-180055

PAIVA, O da C; MOURA, S. Hospedaria de imigrantes de São Paulo. São Paulo: Paz e Terra, 2008. (Coleção São Paulo no bolso). https://doi.org/10.11606/d.8.2013.tde-09122013$\underline{105945}$

PANIZZOLO, C. Livros de leitura, dizeres e fazeres da escola primária étnica italiana no Brasil entre fins do século XIX e início do século XX: o estudo do livro Piccolo Mondo, letture per le scuole elementari. Anais do XI Congresso Luso- Brasileiro de História da Educação. Porto: Centro de investigação transdisciplinar cultura, espaço e memória. 2016. https://doi.org/10.19146/pibic-2015-37185

PEPE, G. La scuola italiana in San Paolo del Brasile. São Paulo: Pocai, 1916.

REVEL, J. Os usos da civilidade. In: ARIÈS, P., CHARTIER, R. (Orgs). História da vida privada: da Renascença ao Século das Luzes - São Paulo: Companhia das Letras, 1999. p.169-210. https://doi.org/10.21669/tomo.v0i0.4918

ROMAGNOLI, F; ALBERTONI, S. Piccolo Mondo: letture per le scuole elementari. Firenze: Bemporad, 1910.

SALVETTI, P. Governo italiano, diplomacia e escolas italianas no exterior. In: LUCHESE, T. (org). História da escola dos imigrantes italianos em terras brasileiras. Caxias do Sul: EDUCS, 2014. p. 57-78. https://doi.org/10.4025/rbhe.v16i1.909

SÃO PAULO. Anuário do Ensino do Estado de São Paulo: publicação organizada pela Inspectoria Geral do Ensino por ordem do Governo do Estado. São Paulo: Typ. Siqueira, 1909. https://doi.org/10.29289/259453942018v28s1057

SCHWARCZ, L. M. O espetáculo das raças: cientistas, instituições e questão racial no Brasil. São Paulo: Companhia das Letras, 2002. https://doi.org/10.5585/eccos.n46.8915

SOCIETÀ DI MUTUO SOCCORSO PRINCIPE DI NAPOLI. Statuto della Società di Mutuo Soccorso Principe di Napoli di San Gaetano. São Paulo, 1922. https://doi.org/10.2307/2220943

TRENTO, A. Do outro lado do Atlântico: um século de imigração italiana no Brasil. São Paulo: Nobel, 1988.

TRENTO, A. In Brasile. In: BEVILACQUA, P; DE CLEMENTI, A.; FRANZINA, E. Storia dell'emigrazione italiana: II Arrivi. Roma: Donzelli Editore, 2009. p. 3-23.

VERONA, F. Vida e morte dos operários de Schio em São Paulo: uma leitura dos Registros Obituários do Cemitério do Brás, de 1893 a 1895. In: CARNEIRO, M. L. T. et alii (orgs). História do trabalho e histórias da imigração. São Paulo: EDUSP/FAPESP, 2010, p. 267298. https://doi.org/10.11606/d.44.2013.tde-18112013-104436 